\title{
HUBUNGAN GAYA HIDUP TERHADAP OVERWEIGHT DAN OBESITAS PADA REMAJA PUTRI DI SMA NEGERI 11 MAKASSAR
}

\author{
The Association Between Lifestyle With Overweight And Obesity \\ Status Of Female Adolescents In High School No 11 Makassar
}

\author{
Hermawati Hamalding. Risna. Rahma Sri Susanti \\ Universitas Indonesia Timur \\ Hermawati_1984@yahoo.com
}

\begin{abstract}
ABSTRAK
Overweight berbeda dengan obesitas. Overweight diartikan suatu keadaan berat badan yang melebihi berat badan normal. Sedangkan obesitas adalah penimbunan lemak tubuh yang berlebihan sehingga berisiko terhadap kesehatan.Penelitian ini bertujuan untuk mengetahui Hubungan Gaya Hidup Terhadap Overweight dan Obesitas pada Remaja Putri di SMA Negeri 11 Makassar. Jenis penelitian yang digunakan observasional dengan rancangan Cross Sectional Study. Populasi dalam penelitian ini berjumlah 216 dengan sampel sebanyak 76 siswi umur 14-17 tahun. Pengambilan sampel secara Proportional Stratified Random Sampling. Analisis data yaitu univariat, bivariat dengan menggunakan uji chi-square, dan analisis multivariate menggunakan uji regresi linear berganda. Hasil penelitian berdasarkan analisis bivariat menyatakan ada hubungan aktivitas fisik terhadap overweight dan obesitas dengan nilai $p=0,018$, fast food $p=0,012$, menonton TV $p=0,031$, penggunaan gadget $\mathrm{p}=0,031$. Hasil analisis multivariat menyatakan pengaruh variabel bebas terhadap variabel terikat secara simultan adalah 23,6\%.Disarankan pada siswi agar lebih mempertimbangkan menu makan yang sesuai kebutuhan energi baik di lingkungan sekolah maupun di luar sekolah.
\end{abstract}

Kata kunci : Gaya Hidup, Obesitas, Remaja

\begin{abstract}
Overweight is different from obesity. Overweight means a state of body weight that exceeds the normal weight. While obesity is excessive accumulation of body fat so that risk to health.This study aims to determine the Lifestyle Relationship Against Overweight and Obesity in Young Women in 11 senior high school makassar. The type of research used was observational with Cross Sectional Study design. The population in this study amounted to 216 with a sample of 76 female students aged 14-17 years. Proportional Stratified Random Sampling. Data analysis was univariate, bivariate using chi-square test, and multivariate analysis using multiple linear regression test.The result of the research based on bivariate analysis stated that there is a relationship of physical activity to overweight and obesity with $p=0,018$, fast food $p=0,012$, watching tv $p=0,031$, using gadget $p=0,031$. The result of multivariate analysis stated that the influence of independent variable to the dependent variable simultaneously is $23,6 \%$. It is suggested for students to consider more about the food menu that suits their energy needs both in school and outside school.
\end{abstract}

Keywords : lifestyle, obesity, Adolescents

\section{PENDAHULUAN}

Obesitas merupakan penyakit kronis yang bersifat multifaktorial dan dapat didefinisikan sebagai kenaikan akumulasi lemak tubuh(Fernández-Sánchez et al., 2011) World Health Organization (WHO) melaporkan bahwa prevalensi obesitas meningkat dua kali lipat dari tahun 1980-2014, tahun 2014 lebih dari 1,9 milyar orang dewasa berusia 18 tahun mengalami kelebihan berat badan atau setara dengan 600 juta orang dewasa 
mengalami obesitas. Sekitar 13\% populasi orang dewasa di dunia (11\% pria dan 15\% wanita) (WHO, 2014).

WHO 2015, mengatakan diantara faktor risiko penyakit yang tidak dapat dikomunikasikan, obesitas terutama berkaitan dengan anak-anak dan remaja yang berusia (berusia di bawah 19 tahun), hal ini karena penyakit obesitas sangat berkaitan dengan berbagai macam kesehatan baik itu penyakit degenerative, yang berdampakk di usia dewasa dan di usia lanjut.(WHO, 2015)

Menurut penelitian ( $\mathrm{Ng}$ et al., 2014) dalam (Wulandari, Lestari, \& Fachlevy, 2017), yang dilakukan secara berkala perubahan prevalensi overweight dan obesitas pada semua populasi di dunia dari tahun 1980 sampai 2013 menunjukkan prevalensi obesitas di Eropa Barat sebanyak 13,9\%. Di Amerika Latin prevalensi obesitas tertinggi di Uruguay sebanyak $18,1 \%$ dan Meksiko sebanyak 10,5\%. Penelitian ini juga menjelaskan bahwa lebih dar 50\% dari 671.000.000 penderita obesitas di dunia terdapat sepuluh Negara yaitu Amerika Serikat, China, India, Rusia, Brasil, Meksiko, Mesir, Jerman, Pakistan, dan Indonesia. Amerika serikat sebanyak 13\%, Cina dan India sebanyak 15\% penderita obesitas di dunia. Dan penelitian ini menunjukkan bahwa $62 \%$ penderita overweight dan obesitas di dunia berada di negara berkembang.

Prevalensi obesitas bayi, anak dan remaja meningkat di semua negara, Dengan kenaikan paling cepat terjadi pada LMICs. Diperkirakan 42 juta anak-anak terkena dampaknya Oleh kelebihan berat badan atau obesitas pada tahun 2013. Di Afrika, perkiraan tingkat prevalensi anak Kelebihan berat badan dan obesitas sebesar 8,5\% pada tahun 2010 (atau 12 juta anak) diproyeksikan meningkat Menjadi 12,7\% pada tahun 2020. Di Asia, tingkat prevalensi 2010 sebesar 4,9\% setara dengan sekitar 18 Juta anak-anak. Jika tren saat ini terus berlanjut, lebih dari 70 juta bayi dan muda Anak-anak akan kelebihan berat badan atau obesitas pada tahun 2025, sebagian besar tinggal di LMICs.(WHO, 2015)

Usia remaja berada dalam transisi dari remaja ke dewasa. Saat ini, dirasakan bahwa obesitas sebagian besar dipengaruhi oleh orang dewasa usia pertengahan. Namun, tren terus meningkat dari obesitas di kalangan orang dewasa muda, seperti ke kantor, ke sekolah/ perguruan tinggi, memulai pekerjaan dan mengembangkan hubungan menjadi jelas bahwa banyak dewasa muda mengalami perubahan gaya hidup yang signifikan. Transisi ini dipandang sebagai waktu pengungsian atau titik kunci dalam perjalanan hidup yang membuat orang dewasa muda rentan terhadap keseimbangan energi yang sering menyebabkan kenaikan berat badan (obesitas), yang mungkin tidak secara langsung pada saat itu tetapi terakumulasi. (Poobalan \& Aucott, 2016).

Prevalensi obesitas Provinsi Sulawesi Selatan berdasarkan umur (13-15) tahun (6,3\% BB lebih dan 2,6\% obese), terutama di Kota Makassar sebanyak 7,3\% BB lebih dan 7,4 obese. Angka obesitas umum masih lebih rendah disbanding angka nasional yang mencapai $19,1 \%$ (8,8\% BB lebih dan 10,3\% obese). Seluruh kabupaten di Kota Makassar memiliki prevalensi obesitas umum di bawah angka nasional, sedangkan prevalensi obesitas umum berdasarkan jenis kelamin (11,5\%) yaitu pada laki-laki lebih rendah daripada perempuan masing-masing yaitu $15,7 \%$ dan $18,4 \%$ (Riskesdas, 2013).

SMA Negeri 11 Makassar salah satu sekolah yang berada di tengah-tengah kota Makassar yang sebagian besar Siswinya yang aktif, sehingga berpeluang untuk makan di luar rumah dan mengkonsumsi makanan siap saji/fastfood termasuk gaya hidup yang serba instan. Dari hasil pengamatan yang dilakukan, terlihat cukup banyak Siswi yang mengalami overweight dan obesitas yaitu sebanyak 30 siswi.

Berdasarkan uraian di atas, maka perlu dilakukan penelitian tentang "Hubungan gaya hidup terhadap Overweight dan Obesitas pada remaja putri di SMA Negeri 11 Makassar".

\section{BAHAN DAN METODE}

Jenis penelitian yang digunakan adalah penelitian Observasional dengan pendekatan cross sectional study yaitu untuk mengetahui hubungan variabel independen dan variabel dependen yang diamati dalam periode waktu yang sama.Penelitian ini dilaksanakan di SMA Negeri 11 Makassar khususnya di kelas X dan XI dan dilakukan pada 
bulan Juni dan Juli. Populasi dalam penelitian ini adalah seluruh siswi kelas X dan XI di SMA Negeri 11 Makassar. Sampel dalam penelitian ini adalah sebagian siswi kelas $X$ dan XI di SMA Negeri 11 Makassar dengan teknik pengambilan sampel secara proportional stratified random sampling sebanyak 140 yang diproporsikan menjadi 76 yang terbagi atas kelas $\mathrm{X}$ sebanyak 36 siswi dan kelas XI sebanyak 40 siswi dan analisis data menggunakan program SPSS dengan uji chi-square dan uji t yaitu untuk mengetahui variabel yang paling berpengaruh diantara variabel lainnya.

Data primer diperoleh dengan cara wawancara langsung kepada resonden dengan menggunakan kuesioner penelitian yang telah disiapkan, menimbang berat badan menggunakan timbangan digital, mengukur tinggi badan menggunakan alat microtoa, serta mengukur lingkar pinggul dengan menggunakan meteran.

\section{HASIL}

Hasil analisis univariat dan bivariat diketahui bahwa dari 76 siswi terdapat terendah tingkat kelas X sebanyak $47,2 \%$ dan tertinggi tingkat kelas XI sebanyak 52,6\%, umur tertinggi 16 tahun sebanyak $48,7 \%$ dan terendah umur 14 tahun sebanyak $5,3 \%$, berat badan tertinggi $53-68 \mathrm{~cm}$ sebanyak $67,1 \%$ dan berat badan terendah $133-148 \mathrm{~cm}$ sebanyak $1,3 \%$, tinggi badan tertinggi $150-157$ sebanyak $60,5 \%$ dan tinggi badan terendah $142-149$ cm sebanyak 9,2\%, lingkar pinggul tertinggi $80-87$ sebanyak $42,1 \%$ dan lingkar pinggul terendah 120-127 sebanyak 1,3\%, lingkar pinggul tertinggi tidak normal sebanyak $61,8 \%$ dan terendah lingkar pinggul normal sebanyak $38,2 \%$, jenis aktivitas fisik tertinggi bermain gadget dan menonton TV sebanyak $14,4 \%$ dan terendah jenis aktivitas fisik aerobik sebanyak $1,7 \%$, tertinggi aktivitas fisik tinggi sebanyak $52,6 \%$ dan terendah aktivitas fisik ringan sebanyak $47,4 \%$, konsumsi fastfood teringgi jenis bakso sebanyak $10,0 \%$ dan terendah jenis hot dog with cheese sebanyak $0,6 \%$, konsumsi fastfood tertinggi berisiko tinggi sebanyak $63,2 \%$ dan berisiko rendah sebanyak $36,8 \%$, menonton TV tertinggi berisiko tinggi sebanyak $61,8 \%$ dan terendah berisiko rendah sebanyak $38,2 \%$, penggunaan gadget tertinggi berisiko tinggi sebanyak $65,8 \%$ dan terendah berisiko rendah sebanyak $34,2 \%$, yang memiliki status berat badan normal sebanyak $60,5 \%$, overweight sebanyak $27,6 \%$ dan obesitas sebanyak $11,8 \%$.

Hasil analisis multivariat dengan menggunakan uji regresi linear berganda terdapat pengaruh Aktivitas fisik, Konsumsi fastfood, Menonton TV, dan Penggunaan gadget terhadap Status Berat Badansecara simultan bahwa diketahui nilai Sig. aktivitas fisik terhadap status berat badan sebanyak $0,021<0,05$ dan nilai t hitung $-2,359>\mathrm{t}$ tabel 1,996, fastfood sebanyak $0,056>0,05$ dan nilai $t$ hitung $1,943<t$ tabell 1,996 , menonton tv sebanyak 0,185 >0,05 dan nilai t hitung 1,339<t tabel 1,996, dan penggunaan gadget sebanyak $0,079>0,05$ dan nilai $t$ hitung 1,780 < t tabel 1,996. Hal ini dapat disimpulkan bahwa variabel yang paling berpengaruh terhadap status berat badan remaja dengan adalah aktivitas fisik dengan nilai Sig. sebanyak 0,021<0,05 dan nilai $t$ hitung $-2,359>t$ tabel 1,996.

\section{PEMBAHASAN}

Aktivitas fisik merupakan gerakan anggota tubuh yang menyebabkan pengeluaran energi yang sangat penting bagi pemeliharaan kesehatan fisik dan mental, serta mempertahankan kualitas hidup agar tetap sehat dan bugar sepanjang hari. Aktivitas fisik adalah hal yang dianjurkan bagi setiap orang untuk mempertahankan dan meningkatkan kesegaran serta kebugaran tubuh.

Berdasarkan hasil analisis, aktivitas fisik pada remaja overweight dan obesitas menunjukkan adanya perbedaan. Rendahnya aktivitas fisik pada remaja overweight dan obesitas dalam penelitian ini berkaitan dengan perilaku sedentary lifestyle. Remaja yang overweight dan obesitas lebih banyak melakukan aktivitas pasif seperti menonton televisi, bermain gadget atau laptop, tiduran disertai mendengarkan lagu. Dan rata-rata mereka menghabiskan waktu 3-5 jam di luar jam sekolah dalam melakukan kegiatan sedentary seperti di atas di bandingkan remaja yang status berat badannya normal yang hanya menghabiskan waktu 1-2 jam. Sementara tingginya aktivitas fisik pada remaja dengan berat 
badan normal disebabkan karena keikutsertaan mereka dalam kegiatan ekstrakurikuler terutama basket dan volly yang merupakan jenis kegiatan dengan aktivitas tinggi. Sementara remaja yang berat badan normal yang memiliki aktivitas ringan lebih banyak mengikuti ekstrakurikuler seperti paduan suara.

Untuk mengetahui adanya hubungan antara konsumsi aktivitas fisik terhadap overweight dan obesitas. Dari hasil uji chi square, didapatkan nilai $p$ 0,018 maka dapat disimpulkan ada hubungan konsumsi aktivitas fisik terhadap overweight dan obesitas pada remaja putri di SMA Negeri 11 Makassar.

Penelitian ini sesuai dengan penelitian yang dilakukan oleh Garnis Retnaningrum 2015 menyatakan bahwa aktivitas fisik berhubungan dengan status obesitas pada remaja dengan nilai $p=0,000$. Namun terdapat perbedaan hasil penelitian yang dilakukan oleh Lussi Wahyu Putri Utami tahun 2016, menyatakan bahwa tidak ditemukan adanya hubungan antara tingkat aktivitas fisik, screen time dengan kejadian sindrom metabolik pada remaja obesitas dengan nilai $p=0,324$ dan screen time dengan nilai $p=0,233$.

Fastfood adalah makanan bergizi tinggi yang dapat menyebabkan kegemukan atau obesitas terhadap anak-anak maupun remaja yang mengkonsumsi makanan siap saji. Fastfood adalah jenis makanan mudah dikemas, disajikan dan praktis.

Berdasarkan hasil analisis, konsumsi fastfood pada remaja overweight dan obesitas menunjukkan adanya perbedaan. Hal ini dapat terjadi karena fastfood bukan menjadi satusatunya yang merupakan meningkatnya berat badan pada remaja. Namun, jika dilihat berdasarkan karakteristiknya, mereka tidak mengalami obesitas karena tidak memiliki riwayat gemuk dari orang tua, selain itu jika dilihat dari aktivitas fisik yang dilakukan, ratarata melakukan aktivitas fisik $2 x$ seminggu dengan durasi yang cukup. Kemudian disisi lain terdapat siswi yang berisiko rendah mengkonsumsi fastfood namun mengalami overweight dan obesitas. Hal ini dapat terjadi karena remaja yang kurang melakukan aktivitas fisik dan cenderung kurang gerak atau menggunakan sedikit tenaga untuk aktivitas sehariharinya.Sehingga dapat disimpulkan bahwa faktor yang mempengaruhi terjadinya obesitas tidak hanya pada konsumsi fast food, tetapi dilihat dari faktor lainnya seperti riwayat orangtua obesitas, aktivitas fisik, dan lingkungan sekitar.

Untuk mengetahui adanya hubungan antara konsumsi fastfood terhadap overweight dan obesitas. Dari hasil uji chi square, didapatkan nilai p 0,012 maka dapat disimpulkan ada hubungan konsumsi fastfood terhadap overweight dan obesitas pada remaja putri di SMA Negeri 11 Makassar.

Penelitian ini sejalan dengan penelitian yang dilakukan oleh Sheva Arlinda 2015 menyatakan bahwa ada hubungan yang bermakna antara kebiasaan mengkonsumsi fast food terhadap kejadian obesitas pada remaja dengan nilai $p=0,000$.

Menonton TV merupakan salah satu kegiatan dengan menggunakan mata untuk memandang/ memperhatikan televisi. Menonton televise adalah salah satu bentuk aktivitas fisik pasif yang dimana remaja hanya mengeluarkan usaha dirinya, menonton televise tidak membutuhkan banyak energi melebihi proses metabolism istirahat.

Berdasarkan hasil analisis, kegiatan menonton tv pada remaja overweight dan obesitas menunjukkan adanya perbedaan. Berdasarkan keterangan di atas remaja overweight dan obesitas yang berisiko rendah, menonton televise bukan menjadi satusatunya penyebab dari obesitas, hal ini dapat terjadi karena mereka lebih senang menghabiskan waktu luang dengan menonton televise dan bermain games, dan dibarengi dengan mengkonsumsi cemilan. Sebagian besar waktu senggang dihabiskan untuk bersantai dibandingkan dengan berolahraga. Pada hari sekolah lebih banyak menghabiskan waktu untuk duduk diam dan belajar, sedangkan pada hari libur lebih cenderung untuk menonton tv. Dengan demikian aktivitas fisik cenderung tidak aktif.Berdasarkan keterangan di atas remaja yang berat badan normal berisiko tinggi menonton tv terhadap overweight dan obesitas, hal ini dapat terjadi karena menonton tv bukan merupakan satu-satunya penyebab obesitas namun, remaja yang menonton tv, sebagian waktu mereka imbangi dengan menyibukkan diri dengan aktivitas sehari-hari di rumah seperti membersihkan dan berjalan- jalan, yang merupakan aktivitas yang termasuk sedang. Pada hari sekolah mereka lebih cenderung mengikuti kegiatan ekstrakurikuler. 
Untuk mengetahui adanya hubungan antara menonton tv terhadap overweight dan obesitas. Dari hasil uji chi square, didapatkan nilai p 0,031 maka dapat disimpulkan ada hubungan menonton tv terhadap overweight dan obesitas pada remaja putri di SMA Negeri 11 Makassar.

Hasil penelitian ini sejalan dengan penelitian yang dilakukan oleh Chen dkk 2013, menyatakan bahwa ada hubungan screentime, serta paparan televisi/video, game di komputer, dan telepon genggam dengan kejadian obesitas pada remaja dengan nilai $p=$ 0,0001 .

Kemajuan teknologi yang menjadikan hampir setiap remaja menggunakan gadget sekarang ini. Hal tersebut sangat berpeluang dalam perubahan perilaku makan yang dapat berisiko pada berat badan remaja.Obesitas pada remaja dapat dipengaruhi oleh gaya hidup dan kurangnya aktivitas fisik karena rendahnya aktivitas selama di sekolah dan setelah pulang sekolah siswa jarang sekali melakukan aktivitas fisik seperti olahraga dan berjalan, sebagian besar dari mereka lebih suka melakukan aktivitas fisik pasif seperti duduk, menonton tv, komputer, dan menggunakan handphone bhkan malas untuk bergerak.

Berdasarkan hasil analisis penggunaan gadget dalam penelitian ini adalah tingginya durasi penggunaan gadget pada remaja overweight dan obesitas dalam penelitian ini disebabkan oleh banyak faktor selain hanya aktivitas fisik yang kurang seperti bermain gadget atau menonton tv, konsumsi makanan yang tidak sehat merupakan salah satu penyebabnya. Hal ini disebabkan karena sebagian besar remaja ketika jam pelajaran kosong mereka hanya duduk-duduk di kelas berkumpul dengan teman-teman dan jajan di kantin sekolah. Berbeda dengan remaja yang status berat badannya normal namun durasi penggunaan gadgetnya tinggi, karena mereka sebagian besar ketika jam pelajaran kosong mereka jalan-jalan di sekitar area sekolah, bermain, dan berlari. Dan ketika tiba di rumah ada yang menghadiri ekstrakurikuler, bersepeda dan jogging di sore hari.Sedangkan rendanya durasi penggunaan gadget pada remaja overweight dan obesitas dalam penelitian ini disebabkan karena waktu yang mereka habiskan untuk bermain gadget berhubungan dengan kebiasaan makan yang buruk seperti meningkatnya konsumsi fastfood, jajan makanan yang tidak sehat. Banyak di antara mereka yang menyukai bermain gadget sambil ngemil yang merupakan risiko terhadap berat badannya.

Untuk mengetahui adanya hubungan antara penggunaan gadget terhadap status berat badan pada remaja. Dari hasil uji chi square, didapatkan nilai p 0,031 maka dapat disimpulkan ada hubungan penggunaan gadget terhadap overweight dan obesitas pada remaja putrid di SMA Negeri 11 Makassar.

Hasil penelitian ini sesuai dengan penelitian yang dilakukan oleh Lanita 2015 menyatakan bahwa terdapat hubungan yang bermakna antara screen time (bermain gadget) dengan status gizi remaja dengan nilai $p=0,035$.

Berdasarkan hasil analisis multivariat terdapat pengaruh aktivitas fisik, konsumsi fastfood, menonton TV dan penggunaan gadget terhadap status berat badan pada Remaja yaitu, dari keempat variabel yang paling berpengaruh terhadap overweight dan obesitas adalah aktivitas fisik dengan nilai $p<0,05$. Namun, tidak terdapat perbedaan antara konsumsi fast food, menonton tv, dan penggunaan gadget.

\section{KESIMPULAN DAN SARAN}

Berdasarkan hasil penelitian yang telah dilaksanankan dapat disimpulkan bahwa ada hubungan antara aktivitas fisik, konsumsi fastfood, menonton TV, dan penggunaan gadget terhadap Status berat badan pada remaja putri dan aktivitas fisik merupakan variabel yang paling berpengaruh terhadap status berat badan pada remaja putri di SMA Negeri 11 Makassar. Disarankan pada siswi agar lebih mempertimbangkan menu makan yang sesuai kebutuhan energi baik di lingkungan sekolah maupun di luar sekolah. 


\section{DAFTAR PUSTAKA}

Acharya, B., Chauhan, H. S., Bala, I., Kaphle, H. P., \& Thapa, S. B. (2016). Body image satisfaction, weight perception and knowledge of obesity among adolescents in Kaski district, Nepal. TAF Preventive Medicine Bulletin, 15(5), 396-400.

Fernández-Sánchez, A., Madrigal-Santillán, E., Bautista, M., Esquivel-Soto, J., MoralesGonzález, Á., Esquivel-Chirino, C., . . Morales-González, J. A. (2011). Inflammation, oxidative stress, and obesity. International journal of molecular sciences, 12(5), 3117-3132.

Ng, M., Fleming, T., Robinson, M., Thomson, B., Graetz, N., Margono, C., . . Abera, S. F. (2014). Global, regional, and national prevalence of overweight and obesity in children and adults during 1980-2013: a systematic analysis for the Global Burden of Disease Study 2013. The Lancet, 384(9945), 766-781.

Poobalan, A., \& Aucott, L. (2016). Obesity among young adults in developing countries: a systematic overview. Current obesity reports, 5(1), 2-13.

Riskesdas. (2013). Riset Kesehatan Dasar.

WHO. (2014). Overweight, Obesity.

WHO. (2015). Interim Report of the Commission on Ending Childhood Obesity.

Wulandari, S., Lestari, H., \& Fachlevy, A. F. (2017). Faktor yang Berhubungan dengan Kejadian Obesitas Pada Remaja di SMA Negeri 4 Kendari Tahun 2016. Jurnal IImiah Mahasiswa Kesehatan Masyarakat, 1(3). 